\title{
Foreign Language Learning, Motivation and the Market Economy
}

\author{
Christina Diamantatou ${ }^{1} \&$ Thomas Hawes ${ }^{2}$ \\ ${ }^{1}$ St Helens College, Water St, St Helens, Merseyside, UK \\ ${ }^{2}$ Universitaet Augsburg, Augsburg, Germany \\ Correspondence: Thomas Hawes, Universitaet Augsburg, Universitaetsstrasse 2, 86135, Augsburg, Germany. Tel: \\ 49-0172-719-5315. E-mail: tomhawes2004@yahoo.co.uk
}

Received: November 26, 2015

Accepted: December 5, 2015 Online Published: December 30, 2015

doi:10.5539/jel.v5n1p95

URL: http://dx.doi.org/10.5539/jel.v5n1p95

\begin{abstract}
This study explores UK students' motivation to study foreign languages, linking unrewarding past learning experiences with attrition rates and posing questions about the influence of official policy and socially structured conditions. 31 Further Education college students were given a questionnaire based on Gardner's (1975) Attitude/Motivation Test Battery and this revealed that a high percentage even of motivated students withdrew voluntarily. We sent questionnaires to all those who had terminated their courses prematurely, leading to the finding that all respondents were in fact false-beginners, had already studied a foreign language at school, and now described the experience as unrewarding. This not only suggests that foreign language students face major challenges, but also that those variables related to the past emotional context around their studies may unfortunately trump positive motivation to learn. They may create negative expectations that finally extinguish this motivation itself.
\end{abstract}

Keywords: FE colleges, foreign languages, motivation, drop-out rates

\section{Introduction}

This study investigates why students drop out of foreign language courses at St Helens College, an FE (Further Education) college on Merseyside, UK. When students withdraw from courses before they are finished, is this related to their lack of motivation, to the difficulty of the studies, to the institution's educational philosophy and methodology, to government policy, or to a combination of factors? For one author of this paper, who teaches at the college in question, these are questions of existential importance. More than this, the very future of foreign language study in England and Wales may be in doubt. Post compulsory education in these countries arguably prioritizes employment issues over the needs of individuals and academics express concern over the emphasis on vocational education, as in the following:

"Vocationalism is a term used to refer to various theories, ideological positions and some simplistic attitudes that have attempted to link the world of work to a greater or lesser extent with education. Such approaches often suggest that, as work is an important part of life, we should find a place for it in schools and colleges" (Armitage et al., 2012, p. 24).

However, vocationalism does not adequately describe the current education system, even though there is increased recognition of service industries. The educational value of foreign language learning and its importance for personal development and an understanding of other cultures (often associated with greater appreciation of one's own culture) has seen an increased interest and become a major component of EU educational policy. In fact, the EU's Lisbon Council of March 2000 prioritised Modern Foreign Languages (MFL) among the basic skills, favouring the study of at least two from an early age and calling for a firm commitment to language learning. Unfortunately the British National Language Strategy diverged from this aim. From autumn 2004, the study of MFL in secondary schools was relegated to a non-compulsory entitlement (OFSTED, 2004), resulting in a steep decline in the number of pupils taking languages to GCSE. Although the Government encouraged schools, further and higher education institutions to work together in inspiring pupils to take languages, funding provision actually betrays a very meager commitment to promoting multilingualism in practice:

"A bewildering array of White Papers, Green Papers and discussion documents appears relating to FE and work based training. Some are heavy in rhetoric, but offer little in terms of policy changes that are 


\section{likely to make a real difference" (Coles, 2004, p. 22).}

Where, previously, they had belonged to the public sector, FE institutions now have to take account of certain aspects of private enterprise. The search for improved economic efficiency means changes in structure, management and functioning in a reactive rather than proactive response to change. Uncertainty is accelerating the change in focus to practicalities rather than professional growth. In this volatile environment the learner is caught between humane educational ideals and economic reality, increasingly viewed - in line with the latter-as a unit of economic investment. On a more positive note, many students continue to espouse the educational value of foreign languages, displaying an appreciation of cultural differences and an ability to look outward by enrolling on language programmes. Nevertheless, while theorists claim that life skills, including foreign languages, increase cognitive ability through mental flexibility, higher order thinking skills and problem solving, students are withdrawing from language classes at worrying rates.

This study explores possible reasons for students' withdrawal from foreign languages and looks at intervention strategies that might help prevent this withdrawal in the future. We identify the motivation for the students' decision to take language classes and test the hypothesis of a positive correlation between motivation and perseverance. We refer to the views of language practitioners as to why students withdraw from courses. Finally, we discuss our findings and make recommendations for assuring the future vitality of modern foreign language teaching.

\section{The College and the Student Body}

St Helens College is a general education organization in Merseyside, with a student body of approximately 15,000 full and part time students, diverse in social background and previous academic achievement. According to MATRIX (2007), the college provides an accessible range of high quality educational training and services that match the needs of learners, the economy and the local community. All fourteen areas of learning are funded by the Learning \& Skills Council (LSC). The subject matter at St Helens College prioritizes linguistic intelligence (Gardner, 1985) and is not directly linked to a vocational qualification. However, while St Helens College has been successful in increasing its efficiency, it has lost various language programmes, leading in turn to a loss of students and lecturers. Clearly, some objectives need to be revisited because this conflict between organizational needs and those of individuals results in reduced opportunities for personal growth through education.

\section{Motivation: A Brief Review of the Literature}

All forms of behaviour are thought to be activated by goal-directed incentives and there is consensus that the interactivity between internal and external factors has a strong effect on motivation.

\footnotetext{
"Motivation is the reason or reasons for engaging in a particular behaviour, especially human behaviour as studied in psychology and neurophysiology. These reasons may include basic needs such as food or a desired object, hobbies, goals, state of being, or ideal or may also be attributed to less apparent reasons such as altruism or morality" (Huitt, 2001, p. 11).
}

What is not yet fully understood is whether motivation has a primary or secondary influence on behavior and we, therefore, hope to make a small contribution to researching this issue. On the other hand, it is already established that motivation influences behaviour differently to emotion, which is not usually goal-oriented. Maslow (1954), taking a humanistic perspective, emphasizes the cognitive factors that affect behaviour. His hierarchy of needs, one of the most cited theories, often displayed as a pyramid, puts basic needs at the bottom. Transcendence that goes beyond human behaviour appears at the top and is the highest level of self-actualization. As individuals progress up the pyramid they develop growth needs that, according to Maslow (1954, p. 12), do not stem from a lack of something but, rather, from a desire to grow. This view appears to suggest that individuals engage in activities because they are intrinsically pleasing and not because there are rewards attached to them, i.e., the attraction stems from intrinsic satisfaction. Although Maslow's theory is considered rather vague and therefore difficult to explore via experimentation, it remains influential.

\subsection{Intrinsic Motivation}

Intrinsic motivation, the urge to be involved in an activity for its own sake (Ur, 1991), is thought to be highly desirable in initiating and sustaining engagement. The debate around intrinsic and extrinsic motivation (the latter referring to actions that are initiated in order to achieve some instrumental end, Deci \& Ryan, 1985) is still ongoing, suggesting that both factors may be important in promoting psychological growth. Moreover, external inducement as opposed to satisfaction is central in extrinsic motivation, stressing the role of incentives that may fuel determination. According to Deci and Ryan's (1985) self-determination theory, lack of determination may 
lead to amotivation. However, the distinction between satisfaction and reward need not be a dichotomy as both are equally linked to a need for achievement.

\subsection{Motivation in Foreign and Second Language Learning}

Traditionally, foreign language aptitude was considered a stable ability that was not susceptible to training and was independent of past language learning experiences (Skehan, 1998, p. 15). More recently, cognitive psychology has gained considerable influence in foreign language teaching. Gardner and Lambert's (1972) socio-educational model of second language motivation underlines the influence of learners' social dispositions towards the target language community on their success in learning that language. Carroll $(1981$, p. 2) identifies four components of language aptitude: phonetic coding ability, grammatical sensitivity, rote learning ability (defined as the ability to learn associations between sounds), and inductive language learning, i.e., the ability to infer grammatical rules by comparing similar language items. Again, the basic assumption of this approach is that foreign language learning ability is innate and, therefore, unaffected by experience. However, as Gardner and Lambert explain, when measures of aptitude are correlated with grades in language courses, the validity coefficients show considerable variability, suggesting that variables other than linguistic aptitude are involved. They also argue that "motivation and interest play more important roles in second language acquisition" (p. 266).

Deci and Ryan (2002) investigate individuals' inner growth tendencies. Self-determination theory is concerned with the psychological needs that affect choices rather than influences that are external to the individual. The early issue of extrinsic motivation as an antagonistic counterpart was resolved in Deci and Ryan's (1985) Organismic Integration Theory, which considers the contexts that extrinsically motivated behaviour occurs in and how they may allow for assimilation. Extrinsically motivated behaviours may become part of personal values and beliefs and be fully internalized if feelings of relatedness and competence are experienced by the individual. This need for autonomy and competence, which is thought to underlie intrinsic motivation (Deci, 1975), generated interest into how these affective variables may be a source of support for learning. Theorists who espouse the view that students' feelings of personal competence result in increased motivation argue that such feelings may contribute to the development of achievement behaviour (Elliot \& McGregor, 1999, p. 4) and that it may, therefore, be possible to predict students' degree of perseverance.

Gardner's (1985) motivation construct stresses the predictive power of integrativeness, i.e., a positive disposition towards the target language community: "students' attitudes towards the specific language group are bound to influence how successful they will be in incorporating aspects of that language" (Gardner, 1985, p. 6). A second component within this social dimension, instrumental orientation, involves personal advantages for learners such as professional and/or economic growth. This measure is "the extent to which an individual works or strives to learn the language because of a desire to do so and the satisfaction experienced by this activity" (ibid: 10). This concept seems empowering as it suggests that the individual can control the process. Furthermore, it is based on extensive social psychological research by Gardner and others.

Gardner was also responsible for the development of what would become the most frequently used standardized instrument, the Attitude/Motivation Test Battery, or ATMB (1958). Gardner and Smythe (1975) later extended the original items investigated by a concern with internal consistency and reliability. Central to Gardner's model, especially with regards to developing communicative skills, is integrative motivation, which he regards as the key for long term success in foreign language learning. However, other researchers hold that instrumental motives may be more influential in promoting language proficiency. Gardner later (e.g., 2001) acknowledged that additional factors, such as contextuality, learner anxiety and self confidence, may also affect achievement.

Another interesting study aiming to compensate for the limitations of Gardner's traditional construct is Schumann (1986). While recognising the importance of instrumental and integrative motives as tools for achievement, Schumann's acculturation theory claims that success depends on the degree to which learners acculturate to the target language group. Despite the difficulty of testing this model, acculturation is still considered to be one of the major aspects influencing foreign language learning. Furthermore, skepticism about Gardner's integrative factor arises from its inapplicability to certain situations, for example in contexts where a foreign language is studied as an extracurricular activity. Dickinson (1995), for one, therefore favors the more general distinction of intrinsic and extrinsic motivation. Nevertheless, Gardner's model of motivation remains popular, largely because it has been extensively corroborated by empirical research (e.g., Dörnyei, 1994).

In competence theory (White, 1959), intrinsic motivation is thought to increase if feelings of competency are experienced by the individual. Since the impact of perceived competence with other motivational clusters have not been sufficiently researched as possible contributing factors to foreign language perseverance in post compulsory education, the present study aims to investigate selected motivational variables and the extent to 
which they correlate with classroom retention. While we do not address extroversion or social class, we aim, instead, to establish a causal relation between motivation and student retention. We also canvass teachers' beliefs about the reasons for students' withdrawal from their studies. The main purpose of the study is to highlight the challenges that foreign language learners face and the extent to which these challenges may affect their ability and willingness to learn.

\section{Methodology}

Initial classroom observations and informal chats with students over a period of 5 years indicated a possible correlation between motivational variables and withdrawal. This developed into statistical research on drop-out rates and then into an exploratory project on correlations among variables.

\subsection{Research Questions}

This study seeks potential correlations among students' motivation, perceived competence and withdrawal from foreign language courses, employing a three-pronged approach, as follows:

RQ1: What are experienced teachers' perceptions of students' reasons for withdrawal?

RQ2: How do the motivational variables of adult students in further education correlate with perseverance?

RQ3: What is the perceived competence of those adult students in further education who terminated their studies prematurely?

\subsection{Procedure}

Four qualified MFL teachers, each with 10+ years' experience in FE, responded to a survey asking them to share their views on students' reasons for withdrawal by email. 31 adult learners from affluent areas in Merseyside, with English L1, filled out questionnaires. 21 of these learners were enrolled in a first year Italian evening course and 10 were on a first year Italian morning course. All attended the same institution and were taught by the same researcher.

The mediating variable was perceived competence. In order to assess this, students responded to a single item taken from the perceived competence subscales of the Intrinsic Motivation Inventory: "I think I am pretty good at learning a foreign language" on a 5-point Likert scale. The data thus obtained indicated that further investigation of the factors that affect perseverance was necessary. Students who terminated their studies prematurely and had scored low marks on perceived competence were therefore invited in interviews to give their reasons for doing so. It was necessary to ask them to self-select to minimize the risk of objectification-an attitude that regards a person as a commodity (Roberts, 1998). An open-ended question by email was designed to obtain qualitative data on students' reasons for lack of perceived competence. A closed question was included to gauge whether they had studied foreign languages previously.

\subsection{Procedure and Instrumentation}

Items were adapted from Gardner's Attitude/Motivation Test Battery in order to investigate the role of motivational variables in foreign language learning. A questionnaire was administered to student volunteers at the beginning of the academic year 2009-2010 at St Helens College. All participants were beginners, studying Italian as an extra-curricular activity. The questionnaire was administered in the first week of classes and asked them to choose from alternatives on a five-point Likert Scale. The aim was to measure instrumental motivation (interest in assimilating with the target language community) and integrative motivation (utilitarian reasons for learning the target language).

\subsection{Independent Variable}

Demographics: Data were collected on students' employment status from official documentation (enrollment forms). All students were in full-time employment, so it was hypothesized that they would have approximately the same amount of time available to study.

\subsection{Rationale for Conducting Descriptive Research on Teachers'Beliefs}

The purpose of investigating colleagues' perceptions of reasons for withdrawal was to establish whether the intuitive hypothesis - that students' lack of perseverance related to motivation - was accurate and to provide triangulation, bearing in mind that beliefs are said to be the best predictors of the decisions people make (Brown \& Rogers, 2002). Participation in the survey was by email in order to keep imposition to a minimum and thus obtain more answers. The question ("What do you think are the reasons for withdrawal?") was open ended, rather than framed, in the hope of eliciting spontaneous responses. 


\subsection{Rationale for Measuring Motivation Variables}

A short version of the ATMB questionnaire was employed to reduce administration time and avoid causing the participants fatigue that might have interfered with the accuracy of their responses. Since the original instrument had been written for the Canadian context, it was modified to refer to attitudes towards learning Italian and the Italian community. Students' perceived competence to learn a foreign language was also measured with a single item. Finally students who had terminated their studies prematurely were contacted by email and asked to give their reasons for doing so. They were asked if they had previously studied foreign languages and, if so, how they would describe their learning experience, to investigate possible correlations between motivational variables and lack of perseverance.

\section{Data Analysis}

The practitioners' perceptions, assessed through the single item mentioned above, did not validate the initial hypothesis of a correlation between motivation and termination. Nor was the independent variable of students' employment status found to exert any direct influence on perseverance. Correlations were calculated to determine any relationships between instrumental and integrative motivation, perceived competence, and withdrawal. Results indicated no correlation between instrumental and integrative variables and withdrawal. However, even though the study did not examine causal relations, a strong link was evident between low perceived competence and withdrawal. Low perceived competence was found to be predictive of perseverance for the population and, hence, forms the main focus of the discussion in the following section.

\section{Findings and Discussion}

\subsection{Teachers' Beliefs}

Two out of four teachers surveyed believed that students primarily withdraw from courses because of the difficulty of the subject matter, coupled with the pressure of other commitments such as family and work. One teacher cited lack of interest and lack of study time among students, while a final respondent suggested withdrawal might be due to illness, being away on holiday, or moving house. The initial hypothesis of a correlation between motivation and perseverance was thus not supported by the findings, despite its being widely acknowledged in the literature (Stern, 1983, p. 309).

\subsection{Difficulty with Studies}

Difficulties, whether they refer to course structure, content or the total environment (i.e., including the "hidden curriculum") usually relate to students' characteristics. Individual differences may vary from students' orientations, maturity and cognitive styles to psychological factors such as levels of commitment or how well they cope with stress.

The foreign language learner, as discussed by Stern (1983, p. 398), has to come to terms with non-communication. The lack of a safe reference system gives the learner an initial shock, experienced in the earlier stages of exposure to the language, and is followed by language and culture stress that are thought to accompany the learning experience on a formative level. Also, according to Stern (1983, p. 398), learners experience disorientation with regard to linguistic, semantic and sociolinguistic aspects of the target language. In order to overcome the disorientation of the early stage of contact with the language they would therefore need to construct a new reference system and to develop a sense of familiarity and order. This process of orientation, seen as analogous to first language acquisition and social learning, is referred to as "internalization", "interiorisation" or "incorporation". When difficulties experienced at this level are overcome, the learner is eventually able to use the language "creatively" (Stern, 1983, p. 398).

Differences in ability or intelligence are less popular as research areas than they used to be, mainly due to a number of studies which have shown that successful students are no more intelligent on average than those who do poorly (Beard \& Senior, 1980; in Stern, 1983, p. 20). Moreover, cognitive factors such as aptitude, according to the current view, are not a single entity but, rather, a composite of other characteristics that are involved in foreign language learning (Stern, 1983, p. 368). More awareness of individual differences could sensitise teachers to variations in teaching practice in order to cater to all learners.

Despite individual differences or abilities, students rely heavily on the teacher's skills and knowledge. Therefore good interpersonal relationships are of paramount importance. Schumann (1975) draws attention to their dependence on a supportive teacher or friend. He discusses this linguistic and sociolinguistic dependence as an important transitional phase that would lead to intuitions regarding (in)correctness and, thus, independence from the teacher. Moreover, such secure relationships are vital in diagnosing individual students' difficulties that may 
relate to paying attention in the classroom, note taking or knowing precisely what is expected of them. Early diagnoses of the challenges that students face, if approached in co-operation, may help prevent attrition.

\subsection{Family Issues}

Respondents in the survey cited personal factors such as family or work as affecting students' decision to (dis)continue their studies. Although there is no indication whether these family issues refer to problems such as family illness or support, the importance of personal issues is clear. Viewed in terms of the pressures from family relationships or the much needed support, the role of significant others appears to be elemental. Helping students to set their own goals and developing independence may therefore mitigate the problems due to lack of support. The role of the teacher in establishing a supportive, non-threatening environment in which students may develop their potential cannot be stressed enough.

\subsection{Work Issues}

According to the respondents, work-related issues also cause students to drop out. Changes in employment conditions such as having to work longer hours or a work timetable conflicting with class times would affect students' commitment to studying a foreign language unless this was a career enhancement activity. As this is rarely the case with adult language students in post-compulsory education, employment obligations are likely to be prioritised, impacting on the commitment to learn.

\subsection{Learners' Factors}

The respondents' consensus was that lack of perseverance was due to lack of interest and study time on the part of students, as well as their illness, holidays and moving house. Teachers' personal beliefs may affect their decisions about classroom pedagogy and if these beliefs include the notion that learners' factors, rather than the quality of their teaching, are responsible for students' dropping out, this might be a more comfortable explanation to live with as teachers. Therefore it seems that practical experience and theoretical arguments supported by research (Gardner's construct) contradict each other. While the instrument appears to have some face validity (two respondents cited difficulty as the reason for withdrawal), the data do not support the theory that motivation is "high on most teachers' lists" (Williams \& Burden, 1997, p. 111).

This poses the question whether the element of difficulty, considered by the respondents as the main reason for withdrawal, allows for a proactive approach to teaching and an emphasis on humanistic techniques and interpersonal relations. It could be argued that an affective goal would help students to relate learning to their own purposes and perhaps even contribute to the development of achievement behaviour (Elliot \& McGregor, 1999, p. 4). Nevertheless, these findings should be viewed with caution due to the study's limitations, particularly the small sample size. Future research should consider employing a more comprehensive questionnaire administered at different periods (e.g., not only at the end of term, as in this case) to a larger number of informants.

\subsection{The Predictive Nature of Motivational Clusters in Perseverance}

The questionnaire asked students their reasons for studying a foreign language on a 5-point Likert scale, the focus being on integrative and instrumental motivation (Gardner, 1985, p. 6). It was hypothesised that high levels of motivation would correlate positively with perseverance and that students who were integratively and instrumentally motivated would complete their studies while those who had a low score on these measurements would withdraw. In fact no difference was observed between students who persevered $(\mathrm{N}=16)$ and those who withdrew $(\mathrm{N}=15)$. All students had high scores on both measures.

Gardner himself acknowledges that motivation is dynamic. Clearly, the instrumental/integrative distinction is too restrictive (Dörnyei, 1994, p. 274). According to Schumann (1986), while these measures are important motivation is a complex construct interacting with numerous other factors. Interestingly, all students who terminated their studies scored low on the item of perceived competence.

\subsection{Perceived Competence in Relation to Past Learning Experiences}

The hypothesised variable of perceived competence was found to be a predictor of perseverance, supporting the notion that affective variables play a role in achievement behaviour (Elliot \& McGregor, 1999, p. 4) and further suggesting low perceived competence or self-confidence is an indicator of negative perseverance. As to a causal relation, White's (1959) "effectance theory" claims that people need to use their capacities in an effective manner, since it is capacities rather than drives that cause people to actively seek ways of improving themselves.

Earlier deterministic theories that held instinct responsible for behaviour have waned as cognitive processes are increasingly believed to both account for behaviour and to be affected by experience. In Maslow's theory (1954) 
it is growth needs that play a major role in developing certain behaviours. Deci and Ryan (2002) discuss competence, autonomy and relatedness as universal needs motivating behaviour. Teachers should therefore promote interpersonal interaction to foster intrinsic motivation.

\subsection{Self-Concept}

Evidence in the present study points to a link between lack of perseverance and low perceived competence as all students who had terminated their studies indicated that they were false-beginners, suggesting an impact from previous negative learning experiences, although no causal effect could be established. Perceived competence is assigned a mediating role in coping with challenges (Bandura, 1981). Feedback on performance is thought to affect perceptions of competence, which in turn affect intrinsic motivation. In the literature, competence valuation is crucial in sustaining interest in an activity (Deci \& Ryan, 1985).

Feelings of competence also support extrinsically motivated behaviours (Deci \& Ryan, 2002) that are important in promoting psychological growth. According to Bandura (1981), perceived competence depends on information that may consist solely of students' previous academic achievement. The causal contribution of negative learning experiences to low perceived competence on students' ability to learn a foreign language can only be hypothesised here. Nonetheless, the pedagogical implications of negative past learning experiences must be considered when attempting to activate students and to increase their motivation. Those students whose data were used in this report indicated that they had a background of studying languages at school. This involved grammar and translation of sentences, which they reported was unrewarding.

In order to protect students from the negative effect of past experiences and therefore protect their linguistic self-concept, it may be important to devise strategies to maximise positive evaluation and a sense of achievement Feedback can be realised in the form of action or lack of action and can be given by means of praise or silence. In language learning, external reinforcement in the form of rewards or praise is considered a successful way of motivating underachievers. On the other hand, if learners are intrinsically motivated, rewards and praise can have a potentially negative effect (Williams \& Burden, 1997, p. 137). Regardless of whether learners are intrinsically or extrinsically motivated, their willingness to learn will be greatly affected by their perceptions of themselves and the extent to which they believe they are capable of learning, i.e., effectiveness motivation (Williams \& Burden, 1997, p. 136).

\subsection{Achievement in Foreign Language Learning}

Achievement in language learning is many sided as students have differing aspirations. McDonough (1981, p. 155) bemoans the fact that, while some have goals set for them by the educational system, they may not experience any benefit from learning a language until after school, if at all, and growing concern with employment prospects makes studying languages at school even less appealing. McDonough cites success as the most important variable in sustaining learning and connects it to the instructors and how they handle individual students' success or failure.

\subsection{Self-Schemata and Feedback}

Self-schemata provide a basis for predicting behaviour. Thus it might be assumed that students' perceptions about their ability to become successful language learners would be sensitive to teachers' feedback. It is therefore interesting to contemplate the reasons why language learners who returned to the classroom seemed to be unaffected by positive feedback, though all students who terminated their studies prematurely indicated that they had received positive feedback. Whereas individuals with positive "self-schemata" (Taylor \& Boggiano, 1987) tend to ascribe failure to lack of effort, those with negative schemata ascribe it to internal causes. Having been unsuccessful in their first attempt to learn a foreign language, students are probably pessimistic about their ability to learn in the future and allow ingrained avoidance dispositions to influence them, withdrawing as early as in the second week of a course. This raises the question of whether high attrition rates are of any concern to those who influence educational decisions, since the prevailing focus in education appears to value only skills and productivity that contribute to the economy.

\subsection{Education and the Market Economy}

Despite the importance of language learning in EU policy, funding allocation is poor. Managerial efficiency and student statistics are the top priorities for colleges. At St Helens, efficiency seems to be the overriding concern and "doing things right" may be trumping "doing the right things". As Mullins (2005, p. 260) states:

“"Managerial efficiency' can be distinguished from 'managerial effectiveness'. Efficiency is concerned with 'doing things right' and relates to input and what the manager does. Effectiveness is concerned with 'doing the 
right things' and relates to outputs of the job and what the manager actually achieves."

Language practitioners have seen the unwelcome effects of the new arrangements in the loss of work opportunities, while this report suggests that students' (unrewarding) past learning experiences and their perceptions of (in)competence are working against them, even when they are well-motivated. Arguably, therefore, objectives need to be revisited, with more emphasis placed on the needs of students and staff. A first step might be to review Maslow's (1954) "hierarchy of needs", in which the need for safety must be met before attention is turned to satisfying higher order needs. Efforts are needed to empower students and raise their self-esteem by means of praise, which could satisfy their emotional needs and foster intrinsic motivation. In parallel, one institutional factor that might have a motivating effect would be distributing certificates, because foreign language courses in FE are currently unaccredited. This would promote students' extrinsic motivation.

\section{Conclusion}

This study set out to explore selected motivational variables and the extent to which they correlate with retention in language courses. It has considered ways of improving retention rates and countering demotivation. Although the factors involved are varied and ultimately unpredictable, an understanding of the general principles of foreign language learning may provide a useful framework. On the other hand, the Government's [age] 14-19 agenda for education does not appear to be delivering the economic benefits that the recent reforms predict. The new funding model may be negatively affecting MFL departments as students now have to pay a higher fee. A reduction in the size of the student population will affect the funds available for the programmes, with the result that they may not run at all.

Lumby and Foskett's (2005) alternative to the existing model suggests that funds be directed not to student numbers but at funding institutions to offer a range of programmes so as to provide for people's developmental needs.

"The problem we face in improving education is not a matter of dealing with inertia. There is plenty of activity. The problem is that the activity, or innovation, is often not part of a comprehensive or shared vision. The innovation may give a false sense of accomplishment because it is new, but the question hangs in the air: does the innovation make a difference in achieving the desired outcomes for students?” (Erickson, 2002, p. 11).

\section{References}

Armatage, A., Evershed, J., Hayes, D., Hudson, A., Kent, J., Lawes, S., ... Renwick, M. (2012). Teaching and Training in Lifelong Learning (4th ed.). Open University Press.

Bandura, A. (1981). Self referent thought: A developmental analysis of self-efficacy. In J. H. Flavell, \& L. Ross (Eds.), Social Cognitive Development: Frontiers and possible futures. New York: Cambridge University Press.

Beard, R. M., \& Senior, I. (1980). Motivating students. In H. H. Stern (Ed.), Fundamental Concepts of Language Teaching. Oxford: Oxford University Press.

Brown, J., \& Rodgers, T. (2002). Doing second language research. Oxford: Oxford University Press.

Coles, A. (2004). Teaching in Post Compulsory Education. London: David Fulton Publishers.

Carroll, J. B. (1981). Twenty-five years of research on foreign language aptitude. In K. Diller (Ed.), Individual Differences and Universals in Language Learning Aptitude (pp. 83-118). Rowley, MA: Newbury House.

Deci, E. L. (1975). Intrinsic Motivation. New York: Plenum. http://dx.doi.org/10.1007/978-1-4613-4446-9

Deci, E. L., \& Ryan, R. M. (1985). Intrinsic Motivation and Self-Determination in Human Behaviour. New York: Plenum. http://dx.doi.org/10.1007/978-1-4899-2271-7

Deci, E. L., \& Ryan, R. M. (2002). Handbook of Self-Determination Research. Rochester: University of Rochester Press.

Dickinson, A. M. (1989). The detrimental effects of extrinsic reinforcement on "intrinsic motivation". The Behavior Analyst, 12(1).

Dörnyei, Z. (1994). Motivation and motivating in the foreign language classroom. The Modern Language Journal, 78, 273-284. http://dx.doi.org/10.1111/j.1540-4781.1994.tb02042.x

Dörnyei, Z. (2001). Teaching and Researching Motivation. Harlow, England: Pearson Education.

Elliot, A. J., \& McGregor, H. A. (1999). Test anxiety and the hierarchical model of approach and avoidance achievement motivation. Journal of Personality and Social Psychology, 76, 628-644. 
http://dx.doi.org/10.1037/0022-3514.76.4.628

Elliot A. J., \& Church, M. A. (2010). Competence Valuation. University of Rochester, USA. Retrieved from http://www.psych.rochester.edu/research/. Accessed 14.6.2010

Elliot, A. J., Faler, J., McGregor, H. A., Campbell, W. K., Sedikides, C., \& Harackiewicz, J. M. (2000). Competence Valuation as a Strategic Intrinsic Motivation Process. University of Rochester. Retrieved from http://psp.sagepub.com/content/26/7/780.abstract. Accessed 15.6.2010.

Erickson, H. L. (1995). Stirring the Heart, Head and Soul. California: Corwin Press.

Gardner, R. C., \& Lambert, W. (1972). Attitudes and Motivation in Second Language Learning. England: Newbury House.

Gardner, R. C., \& Smythe, P. C. (1975). Second language acquisition: A social psychological approach (Research Bulletin No. 332). London, Ontario: University of Western Ontario, Department of Psychology.

Gardner, R. C. (1985). Social Psychology and Second Language Leaning: The role of attitudes and motivation. London: Edward Arnold.

Huitt, W. (2001). Motivation to Learn: An overview. Retrieved from http://www.martinfrost.ws/htmlfiles/aug2008/motivation.html. Accessed 10.6.2010.

Lumby, J., \& Foskett, N. (2005). 14-19 Education. London: Sage Publications.

Maslow, A. (1954). Motivation and Personality. New York: Harper.

MATRIX. (2007). Quality Standards for Information Advice. Retrieved from http://www.matrixstandard.com/excellenceawards2006/winners/st_helens_college.php

McDonough, S. H. (1981). Psychology in Foreign Language Teaching. London: Allen \& Unwin.

Mullins, L. J. (2005). Management and Organisational Behaviour. Prentice Hall.

OFSTED. (2004). Increased Flexibility Programme at Key Stage 4: Evaluation of the first year. Retrieved from http://www.ofsted.gov.uk/. Accessed 10.6.2010

Roberts, P. (1998). Rereading Lyotard: Knowledge, commodification and higher education. Electronic Journal of Sociology. Retrieved from http://www.sociology.org/content/vol003.003/roberts.html. Accessed 31.5.2010

Schumann, J. H. (1975). Affective factors and the problem of age in second language acquisition. Language Learning, 25, 205-235. http://dx.doi.org/10.1111/j.1467-1770.1975.tb00242.x

Schumann, J. H. (1986). Research on the acculturation model for second language acquisition. Journal of $\begin{array}{lllll}\text { Multilingual and } & \text { Multicultural }\end{array}$ http://dx.doi.org/10.1080/01434632.1986.9994254

Skehan, P. (1998). A Cognitive Approach to Language Learning. Oxford: Oxford University Press.

Stern, H. (1983). Fundamental Concepts of Language Teaching. Oxford: Oxford University Press.

Taylor, J., \& Boggiano, A. K. (1987). The effects of task-specific self-schemata on attributions for success and failure. Journal of Research in Personality, 21, 375-388. http://dx.doi.org/10.1016/0092-6566(87)90018-3

Ur, P. (1991). A Course in Language Teaching: Practice and Theory. Cambridge: Cambridge University Press.

Williams, M., \& Burden, R. (1997). Psychology for Language Teachers. Cambridge: Cambridge University Press.

White, R. (1959). Competence Motivation. Motivation Reconsidered: The concept of competence. Psychological Review, 66, 297-333. http://dx.doi.org/10.1037/h0040934

Williams, M., \& Burden, R. (1997). Psychology for Language Teachers. Cambridge: Cambridge University Press.

\section{Copyrights}

Copyright for this article is retained by the author(s), with first publication rights granted to the journal.

This is an open-access article distributed under the terms and conditions of the Creative Commons Attribution license (http://creativecommons.org/licenses/by/3.0/). 